\title{
Aproximación conceptual al programa ABC
}

\section{Conceptual approach to the $\mathrm{ABC}$ program}

DOI: $10.46932 / \mathrm{sfjdv2n5-121}$

Received in: Oct 1st, 2021

Accepted in: Dec 30th, 2021

\author{
Rocío Muñoz Melgar \\ Graduada en Educación Primaria \\ RG Formación \\ Calle Rosalía de Castro, 44, 30107 Murcia \\ Juani González Muñoz \\ Graduada en Educación Primaria, \\ RG Formación \\ Calle Rosalía de Castro, 44, 30107 Murcia \\ Belén Cánovas Calderón \\ Graduada en Educación Primaria \\ RG Formación \\ Calle Rosalía de Castro, 44, 30107 Murcia
}

\section{RESUMEN}

El trabajo ha sido estructurado en dos bloques temáticos: Marco teórico, e Intervención educativa. En lo referido al primer bloque temático correspondiente al Marco teórico (Bloque I: Marco teórico), llevaremos a cabo una breve revisión bibliográfica que nos ayudará a exponer las ideas fundamentales del Programa ABC a partir de la página oficial del centro educativo CEIP Santa María de Gracia así como de otras páginas webs y documentos hallados a modo de ampliación. Para la realización del segundo bloque temático correspondiente a la Intervención educativa (Bloque II: Intervención educativa), detallaremos los aspectos didácticos y organizativos que se llevan a cabo en el centro para cumplimentar el Programa $\mathrm{ABC}$, desarrollando los aspectos estructurales (apoyo educativo, recursos materiales y recursos espaciales que posibilitan la puesta a punto del Programa), aspectos didácticos (metodología escogida para los procesos de enseñanza aprendizaje, el alumnado destinatario de la aplicación de dicho programa y su finalización en el centro) y aspectos organizativos (recursos personales que posee el centro para la implantación del Programa ABC y los procesos de seguimiento, revisión y evaluación que se llevan a cabo al alumnado destinatario).

Palabras clave: ABC, NEE, NEAE, Atención a la Diversidad, discapacidad auditiva.

\section{ABSTRACT}

The work has been structured in two thematic blocks: Theoretical Framework and Educational Intervention. Regarding the first thematic block corresponding to the Theoretical Framework (Block I: Theoretical Framework), we will carry out a brief bibliographic review that will help us to expose the fundamental ideas of the ABC Program from the official website of the educational center CEIP Santa María de Gracia as well as other websites and documents found as an extension. In order to carry out the second thematic block corresponding to educational intervention (Block II: Educational Intervention), we will detail the didactic and organizational aspects that are carried out in the center to fulfill the $\mathrm{ABC}$ 
Program, developing the structural aspects (educational support, material resources and spatial resources that make possible the implementation of the Program), didactic aspects (methodology chosen for the teaching-learning processes, the target students of the application of this program and its completion in the center) and organizational aspects (personal resources that the center has for the implementation of the ABC Program and the processes of monitoring, review and evaluation that are carried out to the target students).

Keywords: ABC, SEN, SEN, Attention to Diversity, hearing impairment.

\section{MARCO TEÓRICO}

El programa $\mathrm{ABC}$ surgió con la intención de mejorarlas respuestas educativas, ante las necesidades que plantean los alumnos con discapacidad auditiva, en este caso hablamos de que en la Región de Murcia contamos con 400 alumnos con dicha discapacidad en la etapa de escolarización obligatoria.

El principal objetivo del programa $\mathrm{ABC}$ es la enseñanza de alumnos sordos en una escuela inclusiva, donde tengan la oportunidad de relacionarse tanto con compañeros oyentes como con compañeros sordos y que tenga en cuenta su sistema de comunicación preferente, la rehabilitación de la audición, la lengua oral y escrita y la necesidad de intervención especializada para lograr un máximo desarrollo curricular, cognitivo, emocional y social. En el caso de aquellos alumnos sordos que tienen un diagnóstico adicional de discapacidad psíquica, la modalidad de escolarización en el centro es aula abierta.

Encontramos otro tipo de objetivos más específicos en torno al programa $\mathrm{ABC}$ como los siguientes:

\subsection{OBJETIVOS A NIVEL CURRICULAR.}

En principio, con los alumnos sordos debemos perseguir los mismos objetivos y contenidos que con el resto de alumnos. Pero para determinados contenidos y/o objetivos particulares, a juzgar por el logopeda y por el tutor o especialista, y para casos concretos de alumnos sordos, se requerirá su reformulación, aplazamiento o supresión. Esto se refiere a todas las áreas curriculares y aunque no se deben suprimir objetivos, sí se ha de trabajar con una metodología apropiada, que prime la información visual, que sea motivadora y que tenga en cuenta el trabajo por competencias,. Así mismo son fundamentales las adaptaciones de acceso al currículo, la $\operatorname{LSE}^{1}$ y las adaptaciones en los textos.

\footnotetext{
${ }^{1}$ Lengua de Signos Española.
} 


\subsection{OBJETIVOS COMUNICATIVO-LINGÜÍSTICOS.}

Dentro del desarrollo fonológico poder realizar todas las acciones necesarias para conseguir que se desarrolle el lenguaje oral en la medida de lo posible, mediante una rehabilitación logopédica específica.

En cuanto al desarrollo léxico-semántico en las primeras etapas tendremos que trabajar el vocabulario asociado siempre a una imagen. Además será necesario realizar una cuidadosa selección del vocabulario que vamos a enseñar, ya que este debe ser el más cercano a su entorno y lo más funcional posible.

Y por último, respecto al desarrollo morfosintáctico hay que considerar todas las dificultades que los alumnos sordos profundos o severos o implantados con audición poco funcional presentan en relación al aprendizaje de la lengua escrita, trabajamos con una programación y material alternativo basados en los objetivos generales de la etapa de primaria referidos a la adquisición de la lengua escrita, realizando una adaptación del currículo en la que se suprimen ciertos contenidos, pero que fundamentalmente consiste en añadir otros que suponen pasos intermedios para alcanzar los objetivos específicos referidos a expresión escrita y comprensión lectora. En los casos de alumnos con un menor grado de pérdida auditiva y mayor competencia en lengua oral, no será necesaria una adaptación significativa, pero sí un apoyo especializado y en algunas ocasiones, adaptaciones en los textos.

\subsection{OBJETIVOS A NIVEL DE INTEGRACIÓN Y DE SOCIALIZACIÓN.}

Uno de los principales objetivos, es lograr la integración social de los alumnos sordos. Por este motivo es necesario desarrollar en ellos aspectos tan importantes como la autoestima, la necesidad de comunicarse y relacionarse con los demás, la seguridad en sí mismos y la motivación para aprender.

El programa $\mathrm{ABC}$ está dirigido a alumnos con necesidades educativas especiales derivadas de discapacidad auditiva (hipoacusia severa, profunda o con implante coclear), sin discapacidad intelectual asociada y usuario de la lengua de signos española. Para que estos alumnos sean atendidos en base a sus necesidades, el programa es desarrollado por docentes especialistas en audición y lenguaje. También pueden participar profesionales de la intervencion y rehabilitacion de audicion y lenguaje vinculados al movimiento asociativo, cuya actuación puede realizarse en horario lectivo o no lectivo. Por último, mencionar que también participan los profesionales del equipo específico de discapacidad auditiva y docentes que dominan L.S.E.

Como último, cabe destacar que cada alumno incorporado al programa cuenta con un informe psicopedagógico. A lo largo de la escolarización, los Equipos de Orientación Educativa y Psicopedagógica (EOEP), realizan un seguimiento y a su vez una evaluación para detectar posibles problemas en el desarrollo de la medida que afecta de una manera negativa al proceso de enseñanza y aprendizaje del 
alumno y así proceder a su modificación. Los alumnos que se encuentran dentro del programa cuentan con adaptaciones curriculares que pueden ser revisadas en un período de tres meses para amoldar el proceso a las necesidades, cambiantes, del alumno.

\section{INTERVENCIÓN EDUCATIVA}

La intervención didáctica es toda acción llevada a cabo por el docente con la finalidad de enseñar y educar. Esta acción postura al docente con un papel de mediador para ayudar al alumnado en el proceso de enseñanza-aprendizaje. Podemos diferenciar tres aspectos:

\subsection{ASPECTOS ESTRUCTURALES}

\subsubsection{Recursos Materiales}

Hay una gran cantidad de materiales adaptados en el centro referentes a cada una de las áreas curriculares. Estos materiales están en la página web del centro a disposición de cualquier persona que los necesite o esté interesada en ellos.

Uno de los mayores recursos utilizados es el uso de las TIC, para ofrecer un recurso lúdico al alumnado y conseguir de una manera más favorable el aprendizaje.

El uso de las pizarras digitales está suponiendo también un gran recurso para la ayuda del aprendizaje de los niños sordos, ya que suponen un gran soporte visual y que complementan la explicación del profesor y ayudan a asimilar y asentar los conocimientos.

Además, se elaboran diccionarios y vídeos de vocabulario en LSE.

\subsubsection{Recursos Espaciales}

Respecto a los recursos espaciales, en dicho centro reservan 4 plazas durante el periodo de escolarización en los niveles de acceso a Infantil y a Educación Primaria, debido a que dicho centro está considerado como un centro de integración preferente del alumnado sordo.

Como el programa $\mathrm{ABC}$ está integrado en todas las actividades del centro, tanto en las curriculares como las extracurriculares, todas estas se traducen al lengua de signos con la ayuda de intérpretes y las profesoras/es de audicion y lenguaje, este centro también se encuentra adaptado a la hora por ejemplo de las alarmas, ya que existen alarmas luminosas para los niños sordos además de las alarmas con sonido para el resto del alumnado.

Haciendo referencia a todas las dependencias del centro, estas también se encuentran señalizadas en lengua de signos, así como también se incluyen imágenes con signos en las diferentes actividades temáticas que se realizan en el centro con motivos de diferentes acontecimientos, para que el alumnado sordo también pueda participar y además sepan lo que están trabajando y porque. 
Finalmente respecto a las aulas ${ }^{2}$, los alumnos sordos de un mismo nivel, se agrupan en una misma clase, cumpliendo el ratio de hasta 4 alumnos sordos por aula, aunque dicho ratio varÍa según los niveles. Además en dichas aulas, todos los rincones están señalizados con imagenes con lengua de signos, así como todos los materiales del aula. En las aulas, al alumnado sordo se le sitúa donde mejor pueda percibir a través de sus restos auditivos, es decir se le sitúa alejado de las áreas ruidosas. El alumnado sordo tendrá establecido unas rutinas, que facilitara la realización de diversas actividades, además se les animará a que realicen actividades de ocio y de juego, las cuales favorecen la interacción entre alumnos sordos y oyentes.

\subsubsection{Apoyo Educativo}

Haciendo referencia al apoyo que puedan recibir los alumnos sordos, podemos destacar que la modalidad preferente de apoyo se realizará dentro del aula, siempre en coordinación con la tutora, para así favorecer la educación inclusiva. Dicho apoyo consiste en transmitir la información que se está dando en clase en lengua de signos al alumnado sordo. La profesora del programa ABC seguirá la adaptación individual de cada alumno sordo, si este la tuviera, y si no seguirá la programación del aula. Esta utilizara el material de clase, o un material adaptado para cada uno de sus alumnos, según considere. El material adaptado será de su propia elaboración, y también podrá ser utilizado por los demás alumnos del aula, es decir los oyentes.

También existe una modalidad de apoyo fuera del aula, la cual se realizará según criterios previamente establecidos, para reforzar así aprendizajes de forma individual, especialmente para reforzar la lengua oral y la escrita. Esta medida se llevará a cabo cuando el alumno se aparte significativamente del currículo, o bien cuando la intervención con el alumnado sordo puede suponer una molestia para el alumnado oyente.

Respecto a el apoyo de los diferentes recursos personales de los que dispone el centro podemos decir, que el apoyo de las logopedas de ASPANPAL, se realizará preferentemente en horario no lectivo, excepto en algunos casos, este apoyo se realizará siempre fuera del aula, pero con una estrecha coordinación con las profesoras del programa ABC. Además dichos logopedas asistirán a todas las reuniones, tanto de programación como de evaluación que afecten a su alumnado. El apoyo de los intérpretes de lengua de signos se realizará en todas las aulas en las cuales se encuentra alumnado sordo escolarizado, aunque se priorizará su presencia con el alumnado sordo profundo, y todos aquellos que tengan la lengua de signos como sistema preferente de comunicación. Su intervención en el aula se realizará de forma alternativa a la profesora del $\mathrm{ABC}$, y se priorizará en aquellas áreas con mayor carga verbal, además también realizará la interpretación de las actividades extraescolares, o extracurriculares,

\footnotetext{
${ }^{2}$ Espacios físicos de al menos $30 \mathrm{~m}^{2}$.
} 
debera de favorecer la comunicación entre el alumnado sordo y el alumnado oyente, y colaborarán además en la realización de materiales de apoyo signado, es decir canciones, poemas o diccionarios.

Para terminar, apuntar que el equipo específico de discapacidad auditiva atiende de forma sistemática al centro una vez por semana, con al menos dos profesionales, un/a psicopedagoga/o un/a profesora/or de servicios técnicos de la comunidad.

\section{ASPECTOS DIDÁCTICOS}

\subsection{METODOLOGÍA}

En aquellas aulas donde se imparte el programa $\mathrm{ABC}$, cuando se enseña cualquier tipo de vocabulario, además de hacerlo de forma hablada, es explicado en Lenguaje de signos Español e ilustrado con imágenes si es excesivamente complejo. La biblioteca y las aulas de este centro educativo cuentan incluso con diccionarios traducidos a la LSE. Lo que se pretende es que todo el alumnado se sienta interesado por la materia, y contenidos que se están dando en ese momento, para hacer esto posible se pretende que el alumnado también tenga interés por este sistema alternativo de comunicación.

De un modo paralelo a este proceso de enseñanza-aprendizaje dentro del aula ordinaria, se llevan a cabo clases de rehabilitación del lenguaje oral por parte de logopedas procedentes de la asociación ASPANPAL (Asociación de Padres de Niños con Problemas de Audición y Lenguaje) de forma individualizada. En este caso, y como podemos ver en el enlace que hay en la parte inferior, se trabaja el control del soplo, es decir, la salida del aire en la pronunciación de los diversos fonemas. Se intenta que el alumno sienta sus propias vibraciones en las cuerdas vocales cuando por ejemplo, hace sonidos agudos o graves, o cuando habla en voz baja o alta.

En el programa $\mathrm{ABC}$ se prioriza la enseñanza específica en el aspecto de la lectoescritura dado que uno de los mayores problemas o dificultades se presenta en los niveles por los que pasa el niño para su aprendizaje. Dichos niveles son:

- Diferencia letras y números de otro tipo de dibujos, realiza grafismos primitivos.

- El niño constituye hipótesis de cantidad y variedad para que un texto sea legible.

- Hipótesis silábica, dar valor sonoro a cada una de las letras que componen una escritura, cada letra tiene el valor de una sílaba. Los niños escriben pseudopalabras.

- Translación de la hipótesis silábica a la hipótesis alfabética, periodo de investigación e identificación de que las letras representan fonemas.

- Hipótesis alfabética, otorga un fonema para cada grafismo y a partir de ese momento si el desarrollo ha ido siguiendo la normalidad solamente afronta problemas de ortografía. 
Esta enseñanza se realiza siempre que se pueda a través del contacto visual, es decir, mediante el uso de imágenes que representan objetos, acciones, situaciones, etc... Y una vez presentadas, los niños tendrán que decir que observan en dichas imágenes.

Parte fundamental de la metodología es el trabajo de todos los niveles del lenguaje que se especifican a continuación:

- El nivel fonológico.

- El nivel léxico-semántico.

- El nivel morfosintáctico.

- El nivel programático.

Las modalidades de apoyo las reciben dentro del aula ordinaria en su sistema de comunicación preferente. Si algún alumno tiene dificultades con la lengua oral y escrita, entonces es cuando se realiza un refuerzo fuera del aula, de manera individualizada, ya que de esta forma los docentes se aseguran que se realice una mayor profundización de la materia.

A la hora de dar la asignatura de inglés los alumnos sólo necesitan apoyo visual, y la adaptación de los textos. Los apoyos recibidos por parte de los logopedas provienen de la asociación ASPANPAL, se realiza fuera del aula ordinaria en horario no lectivo de ocho a nueve de la mañana o en la hora de comedor.

Debido a la diversidad del alumnado, llevan un Plan de Trabajo Individualizado, a menudo a las adaptaciones solamente son necesarias para el acceso al currículo y la LSE, se hace necesario la adaptación de textos por dificultades de léxico.

En este video ${ }^{3}$ podemos visualizar cómo se desarrolla la metodología en un aula que desarrolla un programa $\mathrm{ABC}$.

\subsection{ALUMNADO DESTINATARIO}

El alumnado al que va dirigido el Programa ABC son aquellos afectados por una discapacidad auditiva. La audición puede medirse a partir de una serie de pruebas auditivas que permiten valorar el grado de sordera. La intensidad de la hipoacusia ${ }^{4}$ se mide en decibelios $(\mathrm{dB})$ y representa el nivel más bajo al que se oyen las distintas frecuencias de sonido. Dentro de las hipoacusias que presenta el alumnado destinatario podemos encontrar varios tipos:

\footnotetext{
3 ceipsanta. (2012). Programa ABC 0001 Recuperado https://www.youtube.com/watch?v=2dDGwXX9V5k\&feature=youtu.be

${ }^{4}$ La hipoacusia se define como la pérdida de la capacidad auditiva produciéndose una dificultad o imposibilidad para oír normalmente. Puede ser unilateral afectando a un solo oído o bilateral si afecta a los dos.
} 
- Hipoacusia severa. La audición se encuentra entre los 70 y 90 dB y el individuo que presenta este tipo de hipoacusia necesita prótesis auditivas o de un implante coclear ${ }^{5}$.

- Hipoacusia profunda. Los afectados carecen de la posibilidad de percibir sonidos por encima de $\operatorname{los} 90 \mathrm{~dB}$.

- Alumnado con implante coclear sin discapacidad psíquica asociada.

En el caso de aquellos alumnos sordos que tienen un diagnóstico adicional de discapacidad psíquica, la modalidad de escolarización en el centro es aula aberta

\subsection{FINALIZACIÓN}

El alumnado que ha realizado su etapa educativa de Educación Infantil y Primaria en un centro donde se lleva a cabo el Programa, a la hor de continuar sus estudio en la Educación Secundaria Obligatoria tiene dos posibilidades, acudir a un instituto que disponga de apoyos o a un instituto que prosiga con el desarrollo del Programa ABC.

El alumnado que escoge esta opción, al igual que el resto de alumnos con necesidades educativas especiales, los alumnos con discapacidad auditiva permanecen la mayor parte del tiempo en el aula ordinaria y reciben apoyos por parte de los especialistas de Audición y Lenguaje y/o Pedagogía Terapéutica, en función de las necesidades de dicho alumno y de los recursos del centro. Muchos institutos que escolarizan alumnos con necesidades de sistemas de comunicación alternativos cuentan también con intérpretes de Lengua de Signos Española.

Para que el alumnado destinatario del modelo educativo que propone el Programa ABC pueda continuar sus estudios una vez finalizada la etapa de Educación Primaria con este modelo, se puso en marcha en el curso 2007/08 el Programa ABC en la etapa de Educación Secundaria Obligatoria en el IES Infante D.Juan Manuel de Murcia. La novedad de este modelo es que el alumnado cuenta con docentes de Educación Secundaria especialistas en deficiencia auditiva y expertos en Lengua de Signos en casi todas las áreas del currículo (excepto Educación Física y Educación Plástica en las cuales la información es transmitida por un intérprete de dicha lengua). También el alumnado destinatario recibe apoyo por parte de logopedas. Como en el programa ABC de Educación Primaria, se encuentran dos docentes en el aula, excepto en las materias de Lengua y literatura y Primera Lengua Extranjera en las que los alumnos con discapacidad auditiva asisten por separado a las clases. Los docentes expertos ejercen también labores de

\footnotetext{
${ }^{5}$ Es un tipo de prótesis que requiere de técnicas quirúrgicas para su instalación. Es un aparato que transforma los sonidos y ruidos del medio ambiente en energía eléctrica capaz de actuar sobre las aferencias del nervio coclear, desencadenando una sensación auditiva en el individuo. Estas señales son procesadas por las diferentes partes que consta el implante coclear, las cuales se dividen en externas e internas.
} 
tutoría, y además se ofrece una asignatura optativa del ámbito sociolingüístico en la que se imparte Lengua de Signos Española a dichos alumnos.

\section{ASPECTOS ORGANIZATIVOS}

\subsection{RECURSOS PERSONALES}

Respecto a los recursos personales, el programa es desarrollado por cuatro profesoras/es de audición y lenguaje, las cuales deben de cumplir un perfil adecuado a las características de dicho programa, también se valorará la experiencia con alumnos sordos, así como su conocimiento en la lengua de signos, y otros sistemas de comunicación con alumnos sordos, estas docentes estarán adscritas a uno de los niveles de la etapa para así poder estar coordinadas/os con los tutores del aula, los cuales también son partícipes de esta medida específica. Serán estas propias maestras de AL, las que intervendrán en el área de lengua, de matemáticas y de conocimiento del medio.

Además, el programa también cuenta con dos intérpretes ${ }^{6}$ de lengua de signos, estas provienen de un convenio que la propia Consejería de Educación mantiene con $\mathrm{FASEM}^{7}$, por lo que no son personal fijo del centro, sino que estas pueden variar con los años, aunque el centro siempre contará con estas dos personas como recursos personales para desarrollar dicho programa. El intérprete de primaria apoyara de forma prioritaria en las áreas de conocimiento del medio y de educación para la ciudadanía

También la ASPANPAL ${ }^{8}$ pone a disposición del centro a dos logopedas, las cuales se centran en la rehabilitación de la audición específicamente, y del lenguaje en general, el cual lo trabajan de una manera individual.

Finalmente en el caso de que existan alumnos sordos que también presenten otra problemática asociada, el programa puede requerir de otros recursos del centro o de recursos externos, ya sean profesores de apoyo de la ONCE, fisioterapeutas etc...

\subsection{PROCESO DE SEGUIMIENTO, REVISIÓN Y EVALUACIÓN}

\subsubsection{Evaluación psicopedagógica}

En primer lugar, cuando un alumno llega nuevo al centro se le realiza una evaluación psicopedagógica. Dicha evaluación es llevada a cabo a partir de los equipos de temprana, el equipo específico de discapacidad auditiva o algún equipo de sector.

\footnotetext{
${ }^{6}$ Una de las cuales atiende el centro a tiempo parcial.

${ }^{7}$ Federación de padres de niños sordos de la Comunidad de Murcia.

${ }^{8}$ Asociación de Padres de niños sordos.
} 
La orientadora del equipo específico de discapacidad auditiva es la encargada de actualizar los datos obtenidos en la evaluación cuando el alumno evaluado realiza un cambio de etapa, a mitad de la etapa de primaria, y cuando se descubre o surge un problema en el proceso de enseñanza aprendizaje que requiere una revisión de las capacidades del alumno.

\subsubsection{Adaptación curricular}

Cada tres meses se lleva a cabo una revisión de las adaptaciones curriculares de los alumnos. Principalmente se revisan los contenidos y objetivos y, si es necesario, en el resto de apartados en el caso de surgir algún acontecimiento que tenga un efecto significativo de manera que altere las condiciones del alumno, por ejemplo, si al alumno se le implanta un implante coclear.

\subsubsection{Familias}

Al final de cada trimestre, a las familias del alumnado con discapacidad auditiva sordos se le entrega junto al boletín de evaluación un informe de aquellos docentes que interactúan con el alumno donde se les explica de manera más detallada los contenidos trabajados, la actitud del alumno en clase, aspectos a mejorar y otras incidencias. 


\section{REFERENCIAS}

Lozano Martínez, J., Alcaraz García, S., y Cerezo Máiquez, M. (2015). Plan de atención a la diversidad (pp. 190-193). Madrid: Alianza.

Franco García, M., y Nogueira Fos, R. (2011). Nuevos escenarios para la educación inclusiva: el proyecto ABC de atención al alumnado sordo. Recuperado de: https://diversidad.murciaeduca.es/publicaciones/diversa2011/docs/17.pdf

Fesormu - Federación de Personas Sordas de la Región de Murcia. Recuperado de: http://www.fesormu.org/

EOEP DISCAPACIDAD AUDITIVA MURCIA. Recuperado de:

https://eoepauditivosmurcia.wordpress.com/

C.E.I.P. Santa María de Gracia. Recuperado de: http://ceipsantamariadegracia.com/

Educación de sordos. Recuperado de: https://educacionsordos.wordpress.com/

Proyecto ABC. Recuperado de: http://proyectoabcinfante.blogspot.com/

Metodología extraida de: https://studylib.es/doc/6852594/programa-abc--una-iniciativa-educativa-parala-comunidad-

López Vicente, T., y Guillén Gosálbez, C. Intervención educativa en el alumnado con discapacidad auditiva Murcia. Recuperado de: http://www.psie.cop.es/uploads/murcia/Intervenci\%C3\%B3n\%20Discap\%20Auditiva.pdf

Zalduendo, P. (2014). Hipoacusia, definición - Tipos de sordera y niveles. Recuperado de: https://www.enfermedadesgraves.com/blog/hipoacusia-definicion-tipos-de-sordera/

Intervención didáctica. el contexto de la intervención. (2015). Retrieved 25 November 2019, from https://es.slideshare.net/MaFerPazyPuente/ma-fernanda-paz-intervencion-didactica-el-contexto-de-laintervencion

ceipsanta. (2012). Programa ABC 0001. Recperado de: https://www.youtube.com/watch?v=2dDGwXX9V5k\&feature=youtu.be

Villamartín, C. E. P. PROCESO DE INTEGRACIÓN AUDITIVA EN NIÑOS CON DEFICIENCIA AUDITIVA.

González, P. M. (2003). Sistemas alternativos y aumentativos de comunicación (SAAC) y accesibilidad: Bases teóricas de los SAAC. Puertas a la lectura, (4), 129-136. 